\title{
The effects of telmisartan alone or with hydrochlorothiazide on morning and 24-h ambulatory BP control: results from a practice-based study (SURGE 2)
}

\begin{abstract}
Gianfranco Parati ${ }^{1,2}$, Grzegorz Bilo ${ }^{1,2}$ and Josep Redon ${ }^{3}$ on behalf of the SURGE Steering Committee
Observational studies have shown that 24-h and morning ambulatory blood pressure (BP) control is low. This large-scale, practice-based study evaluated the effects of telmisartan 40 or $80 \mathrm{mg}$ alone or in combination with hydrochlorothiazide (HCTZ) $12.5 \mathrm{mg}$ on these BP parameters over 8 weeks; treatment was adjusted if clinic BP remained $\geqslant 140 / 90 \mathrm{~mm} \mathrm{Hg}$. A total of 863 patients were evaluated (baseline mean clinic BP, morning and 24-h ambulatory BP: $155 \pm 15 / 93 \pm 10 \mathrm{~mm} \mathrm{Hg}, 137 \pm 15 /$ $83 \pm 11 \mathrm{~mm} \mathrm{Hg}, 133 \pm 14 / 79 \pm 10 \mathrm{~mm} \mathrm{Hg}$, respectively; $68 \%$ were previously treated at baseline). Telmisartan with/without HCTZ significantly reduced the mean morning ambulatory BP $(-8.2 /-4.9 \mathrm{~mm} \mathrm{Hg})$, daytime ambulatory BP $(-8.0 /-4.7 \mathrm{~mm} \mathrm{Hg})$, 24-h ambulatory BP $(-7.9 /-4.7 \mathrm{~mm} \mathrm{Hg})$ and clinic BP $(-22.3 /-13.2 \mathrm{~mm} \mathrm{Hg})($ all $P<0.001)$ in previously untreated and in treated patients who switched to telmisartan and telmisartan/HCTZ. After treatment with telmisartan with/without HCTZ, the morning ambulatory BP control increased from 36.5 to $64.4 \%$; daytime ambulatory BP control increased from 40.8 to $67.6 \%$; $53.0 \%$ of patients achieved 24-h ambulatory BP $<125 / 80 \mathrm{~mm} \mathrm{Hg}$ and $62 \%$ achieved $<130 / 80 \mathrm{~mm} \mathrm{Hg}$ targets. Only $0.8 \%$ (7/863) reported an adverse event. In summary, telmisartan and telmisartan/HCTZ increased smooth 24-h BP control in daily management of hypertension.
\end{abstract}

Hypertension Research (2013) 36, 322-327; doi:10.1038/hr.2012.171; published online 15 November 2012

Keywords: ambulatory blood pressure monitoring; hydrochlorothiazide; morning blood pressure control; telmisartan

\section{INTRODUCTION}

Hypertension is a major cause of stroke, myocardial infarction and cardiovascular mortality. ${ }^{1}$ The peak incidence of these events has been shown to occur in the early morning hours, which coincides with a surge in blood pressure (BP) (known as the early morning BP surge), although a causal link between these phenomena has not been definitively demonstrated yet. $^{2-5}$ Ambulatory BP monitoring (ABPM) can be used to measure BP control throughout the 24-h period. ${ }^{6}$ It can, therefore, be used to monitor early morning BP control, and determine how effective treatments are during this critical period.

Observational studies, such as the Analysis of the Control of Blood Pressure using Ambulatory Blood Pressure Monitoring (ACAMPA) study from Spain, have shown that treated patients with clinic BP control $(<140 / 90 \mathrm{~mm} \mathrm{Hg})$ can still have hypertension in the morning; in this study of 240 treated hypertensive patients, more than $50 \%$ with well-controlled clinic BP had elevated morning BP. ${ }^{7}$ A study conducted in Portugal also showed that 103 treated hypertensive patients with well-controlled clinic BP had poor 24-h and morning ambulatory BP control; 35\% failed to achieve morning ambulatory BP (arbitrarily defined as ambulatory BP $<133 / 85 \mathrm{~mm} \mathrm{Hg}$ ). ${ }^{8}$ It is possible that the low control rates achieved in these treated patients were, in part, due to the use of short-acting agents that could not sustain BP control throughout the 24-h period.

However, some agents can provide 24-h BP control; telmisartan (an angiotensin II receptor blocker) has a long duration of action, which is sustained over the 24-h period. Telmisartan $80 \mathrm{mg}$ has been shown to reduce early morning BP significantly when compared with ramipril $10 \mathrm{mg}{ }^{9,10}$ Telmisartan in combination with the diuretic, hydrochlorothiazide (HCTZ), has also been shown to significantly improve BP control compared with valsartan plus HCTZ; this combination is therefore a useful treatment for improving hypertension control in treated patients over 24 h. ${ }^{11}$

The aim of this observational study (Study of hypertensive population Under treatment with telmisartan in Real clinical conditions with Goal to control the Early morning blood pressure rise-2 (SURGE 2)) was to assess the degree of morning and 24-h ambulatory BP control after treatment with telmisartan alone or in combination

${ }^{1}$ Department of Health Sciences, University of Milano-Bicocca, Milan, Italy; ${ }^{2}$ Department of Cardiology, St Luca Hospital, IRCCS Istituto Auxologico Italiano, Milan, Italy and ${ }^{3}$ Hypertension Clinic, Hospital Clinico, INCLIVA, University of Valencia and CIBER of Obesity and Nutrition C/006, Institute of Health Carlos III, Madrid, Spain Correspondence: Professor G Parati, Department of Health Sciences, University of Milano-Bicocca, San Luca Hospital, Piazza Brescia 20,20149 Milan, Italy. E-mail: gianfranco.parati@unimib.it

Received 11 May 2012; revised 21 August 2012; accepted 3 September 2012; published online 15 November 2012 
with HCTZ in treated and untreated patients with elevated clinic BP. $\mathrm{BP}$ was monitored in a number of ways (clinic, home BP measurements and $\mathrm{ABPM}$ ). This paper reports the ABPM findings.

\section{METHODS}

\section{Study design}

SURGE 2 was an 8-week, prospective, open-label, phase IV study conducted in centers across the Czech Republic, Ecuador, Lebanon and Mexico. The main aim of this observational study was to assess the degree of ambulatory BP control in the morning and over $24 \mathrm{~h}$ in patients treated with telmisartan, or telmisartan plus HCTZ, under real community-based conditions. The study enrolled patients between September 2003 and April 2005, and was performed according to the requirements of good clinical practice and other international and local regulations. The protocol was approved by an independent ethics committee. All patients provided written informed consent to participate.

\section{Study population}

Males or females aged between 18 and 80 years with untreated or treated, uncontrolled hypertension (clinic BP $\geqslant 140 / 90 \mathrm{~mm} \mathrm{Hg}$ ) were included; current antihypertensive therapy had to be stable for $\geqslant 1$ month and all medications had to be taken in a single morning administration. Patients were excluded if they had congestive heart failure, unstable angina, acute myocardial infarction, heart surgery or had a stroke within the previous 6 months, arrhythmia, angioedema associated with angiotensin-converting enzyme (ACE) inhibitors, advanced hepatic or renal impairment, or any other condition that would not allow for safe completion of the protocol. Other exclusion criteria included chronic administration of oral anticoagulants or digoxin and known hypersensitivity to any component of telmisartan or HCTZ. Pregnant, nursing or pre-menopausal women not using birth control were also excluded.

\section{Treatments and BP monitoring}

Patients eligible for treatment (those with clinic BP $\geqslant 140 / 90 \mathrm{~mm} \mathrm{Hg}$ ) were prescribed telmisartan $(40 \mathrm{or} 80 \mathrm{mg}$ ) either alone or in combination with HCTZ $(12.5 \mathrm{mg}$ ) based on the decision of the treating physician. Patients using current antihypertensive treatment could either switch medications or have these agents added to their regimen. Patients were instructed to take their medication once daily between 0700 hours and 1000 hours in the morning.

During screening, all physicians were instructed to measure clinic BP using a mercury sphygmomanometer, and in accordance with guidelines. ${ }^{12,13}$ Measurements were taken three times in the seated position, at 2-min intervals and the mean was used. Those patients with uncontrolled hypertension $(\geqslant 140 / 90 \mathrm{~mm} \mathrm{Hg})$ were then fitted with ABPM monitors (Spacelabs Model 90207; provided by Boehringer Ingelheim International $\mathrm{GmbH}$, Ingelheim, Germany). Automatic readings were taken at 15-min intervals during the day ( 0700 hours to 2300 hours) and at 20-min intervals during the night ( 2300 hours to 0700 hours) over a 24 -h period (defined as ABPM baseline); monitors were then removed by the patient. Recordings with more than $80 \%$ measurements and those with at least one reading per time period during the nighttime and early morning hours were considered valid. Data were recorded electronically and were sent to the reference laboratory for assessment and analysis.

Within a week of undergoing ABPM, patients returned to the clinic. Clinic BP was measured as above (defined as clinic BP baseline). Patients with clinic $\mathrm{BP} \geqslant 140 / 90 \mathrm{~mm} \mathrm{Hg}$ were treated with telmisartan and/or telmisartan plus HCTZ as described. Patients could then attend the clinic again after 4 weeks (this was optional) where medication could be adjusted according to clinic BP control $(<140 / 90 \mathrm{~mm} \mathrm{Hg}$ or $\geqslant 140 / 90 \mathrm{~mm} \mathrm{Hg})$. After 8 weeks of treatment, 24-h ABPM was performed and clinic BP was measured during week 8.

\section{Calculations and reference values}

The change from baseline in mean morning (0600 hours to 1159 hours) systolic and diastolic ambulatory BP and the degree of morning ambulatory BP control (arbitrarily defined as the percentage of patients with ambulatory BP
$<135 / 85 \mathrm{~mm} \mathrm{Hg}$ at baseline and at week 8) were recorded. The mean change from baseline in-clinic BP, daytime ambulatory BP (1000 hours to 2200 hours), nighttime ambulatory BP (0000 hours to 0600 hours) sub-periods defined according to the narrow-fixed interval approach, and 24-h ambulatory BP were also determined. Clinic BP control $(<140 / 90 \mathrm{~mm} \mathrm{Hg})$; 24 -h control (24-h ambulatory BP $<125 / 80 \mathrm{~mm} \mathrm{Hg}$ based on European Society of Hypertension/European Society of Cardiology (ESH/ESC) criteria ${ }^{14}$ and 24-h ambulatory BP $<130 / 80 \mathrm{~mm} \mathrm{Hg}$ based on US guidelines ${ }^{15}$ ) and control during the period of activity (daytime) $(<135 / 85 \mathrm{~mm} \mathrm{Hg})$ and nighttime $(<115 / 70 \mathrm{~mm} \mathrm{Hg}$ ) were recorded. The response rates (defined as a percentage of patients with $\geqslant 10 \mathrm{~mm} \mathrm{Hg}$ reduction in systolic BP (SBP) or diastolic BP (DBP) from ambulatory BP or clinic BP baseline) to telmisartan-based treatments were also measured. At the final clinic visit, patients were asked to rate the efficacy of treatment based on a scale of 'very good' to 'bad'.

Tolerability was assessed by adverse events, which were collected, documented and reported in case report forms. At the final clinic visit, patients were asked to rate the tolerability of telmisartan and telmisartan plus HCTZ, based on a scale of 'very good' to 'bad'. Change from baseline was analyzed using the

\section{Table 1a Patient $(n=863)$ characteristics $^{\mathrm{a}}$ according to previous therapy}

\begin{tabular}{|c|c|c|}
\hline & $\begin{array}{l}\text { Previously untreated } \\
\text { patients }(\mathrm{n}=278)\end{array}$ & $\begin{array}{l}\text { Previously treated patients } \\
\qquad(\mathrm{n}=585)\end{array}$ \\
\hline Age, years & $55(12.2)$ & $60(11.7)$ \\
\hline Male, \% & 43.9 & 37.3 \\
\hline $\mathrm{BMI}, \mathrm{kg} / \mathrm{m}^{2}$ & $27.7(5.6)$ & $29.2(19.2)$ \\
\hline Clinic SBP, mm Hg & $157(11.5)$ & $154(15.3)$ \\
\hline Clinic DBP, $\mathrm{mm} \mathrm{Hg}$ & $92(9.1)$ & $93(9.5)$ \\
\hline Morning SBP, mm Hg & $138(14.2)$ & $137(15.1)$ \\
\hline Morning DBP, mm Hg & $85(10.2)$ & $82(10.8)$ \\
\hline Daytime SBP, mm Hg & $138(14.0)$ & $136(14.5)$ \\
\hline Daytime DBP, mm Hg & $85(10.5)$ & 80 (10.6) \\
\hline 24-h SBP, mm Hg & $134(13.8)$ & $133(14.4)$ \\
\hline 24-h DBP, mm Hg & $81(10.1)$ & $78(10.0)$ \\
\hline $\begin{array}{l}\text { Morning heart rate, beats } \\
\text { per min }\end{array}$ & $79(10.3)$ & $75(11.4)$ \\
\hline $\begin{array}{l}\text { Clinic heart rate, beats } \\
\text { per min }\end{array}$ & $76(8.3)$ & $74(9.4)$ \\
\hline $\begin{array}{l}\text { Family history of CV } \\
\text { disease, } \%\end{array}$ & 15.8 & 25.8 \\
\hline Hypercholesterolemia, \% & 21.2 & 39.0 \\
\hline Diabetes, \% & 5.8 & 20.0 \\
\hline $\begin{array}{l}\text { Coronary heart } \\
\text { disease, \% }\end{array}$ & 2.2 & 15.7 \\
\hline $\begin{array}{l}\text { Left ventricular } \\
\text { hypertrophy, \% }\end{array}$ & 5.8 & 23.8 \\
\hline TIA/stroke, \% & 0.4 & 4.8 \\
\hline Heart failure, \% & 0.4 & 2.4 \\
\hline Albuminuria, \% & 3.2 & 4.8 \\
\hline
\end{tabular}

\begin{tabular}{lr} 
Antihypertensive therapy ${ }^{b}, \%$ & \\
ARB & 20.5 \\
Diuretic & 24.6 \\
ACE inhibitor & 42.2 \\
$\beta$-blocker & 34.0 \\
Calcium antagonist & 34.9 \\
Other & 8.7 \\
\hline
\end{tabular}

Abbreviations: $A C E$, angiotensin-converting enzyme; $A R B$, angiotensin II receptor blocker: $\mathrm{BMI}$, body mass index; CV, cardiovascular; DBP, diastolic blood pressure; SBP, systolic blood pressure; TIA, transient ischemic attack. pressure; TIA, transient ischemic attack.
aMean \pm s.d. unless otherwise stated.

${ }^{\mathrm{a}} \geqslant 1$ antihypertensive agent. 


\section{Screening}

Patients $(n=863$ ) with clinic BP $\geq 140 / 90 \mathrm{~mm}$ Hg supplied with ABPM monitors

Morning, daytime, nighttime, and 24-h ambulatory BP recorded (baseline values)

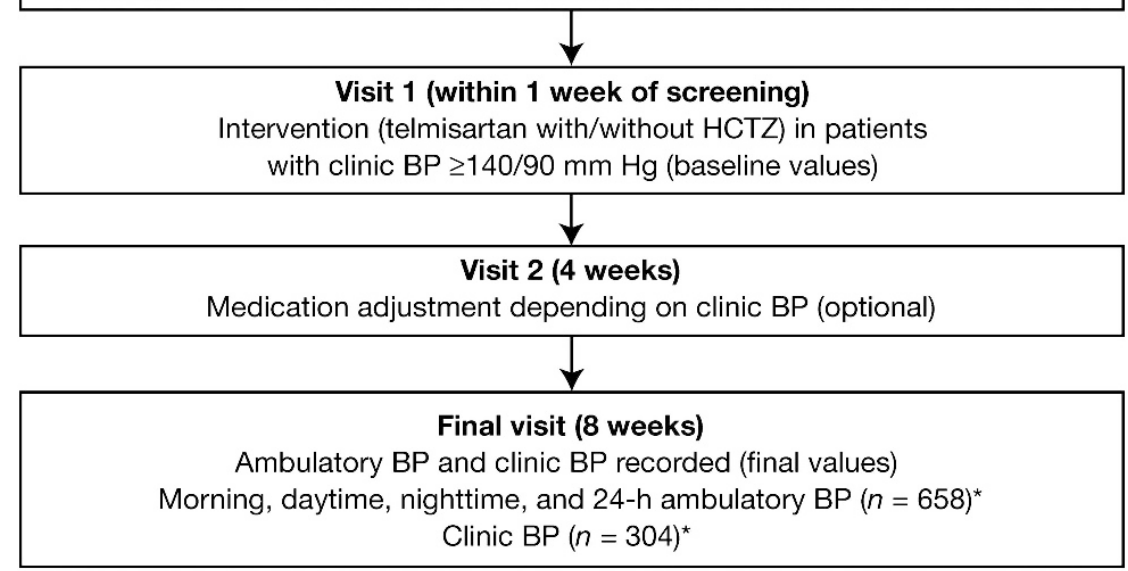

"Patients using only telmisartan with or without HCTZ with measurements available for analysis at final visit

Figure 1 Study design and patient disposition $(n=863)$.

Student's $t$-test for paired data and the ambulatory BP control achieved at final visit was stratified according to clinic BP control using Chi analysis. All patients who received telmisartan or telmisartan plus HCTZ but no other therapy at week 8 and had morning ambulatory BP available at week 8 were included in the analyses.

\section{RESULTS}

\section{Population}

A total of 863 subjects (mean age: 58 years; 39\% male) were included in the ABPM arm of the study. The patient baseline characteristics are shown in Table 1a. The patients were from Ecuador $(55.5 \% ; n=479)$, the Czech Republic $(17.7 \% ; n=153)$, Mexico $(14.7 \% ; n=127)$ and Lebanon $(12.1 \% ; n=104) ; 60.4 \% \quad(n=521)$ had at least one comorbid condition; the most common was hypercholesterolemia (33.3\%; $n=287)$. The majority of patients were taking at least one antihypertensive agent $(67.8 \% ; n=585)$; the most commonly prescribed were ACE inhibitors (42.2\%) and calcium antagonists (34.9\%). Previously untreated patients were younger than previously treated patients (55 vs. 60 years) with more males in this group (43.9\% vs. $37.3 \%)$, and with a lower incidence of comorbid conditions including diabetes (5.8\% vs. $20.0 \%)$.

The study design is illustrated in Figure 1. At the start of the study, $71.1 \%(n=614)$ of patients were given telmisartan and $28.3 \%$ $(n=245)$ were given telmisartan plus HCTZ; treatment allocation was not known for four patients. At final visit, 59.7\% $(n=515)$ were receiving telmisartan and $40.3 \%(n=348)$ were receiving telmisartan plus HCTZ. At final visit, 59.4\% $(n=165 / 278)$ of previously untreated patients were on telmisartan only and $32.4 \%(n=90 / 278)$ of previously untreated patients were on telmisartan plus HCTZ only. In comparison, $40.2 \%(n=235 / 585)$ of previously treated patients were on telmisartan only and $28.7 \%(n=168 / 585)$ of previously treated patients were on telmisartan plus HCTZ only. Only $23.8 \%$ (205/863) had one new antihypertensive (other than study medication) added during the follow-up period. In the previously untreated subgroup, 9 patients were on telmisartan and other antihypertensive medication, and 14 on telmisartan and HCTZ and other antihypertensive medication. In the previously treated subgroup, 106 patients were on telmisartan and other antihypertensive medication, and 76 on telmisartan and HCTZ and other antihypertensive medication at final visit (Table 1b). In total, 29\% (250/863) of patients were also treated with an ACE inhibitor during the follow-up period. There were 54 withdrawals (patients could withdraw for more than one reason; the main reasons were insufficient decrease of BP $(n=9)$, no further patient contact $(n=4)$ and 'other' $(n=8))$. A total of 658 patients had morning, daytime, nighttime and 24-h ambulatory BP data available at final visit and were only using telmisartan or telmisartan plus HCTZ. A total of 304 patients using only telmisartan or telmisartan plus HCTZ had clinic BP measurements available at final visit.

\section{Reductions in ambulatory BP and clinic BP}

Significant $(P<0.008)$ reductions in mean morning ambulatory BP, daytime ambulatory BP, 24-h ambulatory BP and clinic BP were observed after 8 weeks of treatment with telmisartan and telmisartan plus HCTZ for both previously untreated and treated patients (Table 2). There were significant reductions in the mean morning ambulatory BP $(-8.2 /-4.9 \mathrm{~mm} \mathrm{Hg})$, daytime ambulatory BP $(-8.0 /-4.7 \mathrm{~mm} \mathrm{Hg}), 24-\mathrm{h}$ ambulatory BP $(-7.9 /-4.7 \mathrm{~mm} \mathrm{Hg})$ and clinic BP $(-22.3 /-13.2 \mathrm{~mm} \mathrm{Hg})$ (all $P<0.001)$ following the addition of telmisartan and telmisartan plus HCTZ. In previously untreated patients, the mean ambulatory SBP/DBP reductions observed were consistent throughout the 24 -h period for patients treated with telmisartan or telmisartan plus HCTZ. In this population, the mean ambulatory SBP/DBP reductions observed with telmisartan were comparable to those observed with telmisartan plus HCTZ across all measurements. In previously treated patients, the mean ambulatory SBP/DBP reductions were also consistent over the 24-h period; however, the mean reductions were higher for patients treated with telmisartan plus HCTZ than telmisartan alone.

\section{BP control and response rates}

All ambulatory BP and clinic BP control rates increased in both previously untreated and treated patients following the addition of telmisartan or telmisartan plus HCTZ (Table 3). There was a two-fold increase in the morning ambulatory BP control $(<135 / 85 \mathrm{~mm} \mathrm{Hg})$ following the addition of telmisartan-based treatments (from 36.5 to 
$64.4 \%$ (all patients)), and daytime ambulatory BP control improved from 40.8 to $67.6 \%$ (all patients). There were substantial improvements in 24 -h ambulatory BP control; from 25.7 to $53.0 \%$ for $24-\mathrm{h}$

Table 1b Treatment allocation at final visit $(n=863)$

\begin{tabular}{lr}
\hline Subgroup & Patients, $n$ \\
\hline Previously untreated & 165 \\
Telmisartan only & 9 \\
Telmisartan and other antihypertensive medication & 90 \\
Telmisartan and HCTZ only & 14 \\
Telmisartan and HCTZ and other antihypertensive medication & \\
& 235 \\
Previously treated & 106 \\
Telmisartan only & 168 \\
Telmisartan and other antihypertensive medication & 76 \\
Telmisartan and HCTZ only & \\
Telmisartan and HCTZ and other antihypertensive medication &
\end{tabular}

Abbreviation: HCTZ, hydrochlorothiazide. ambulatory BP target $<125 / 80 \mathrm{~mm} \mathrm{Hg}$, and from 36.2 to $62.0 \%$, where the 24-h ambulatory BP target was $<130 / 80 \mathrm{~mm} \mathrm{Hg}$. Clinic BP control $(<140 / 90 \mathrm{~mm} \mathrm{Hg})$ also increased from 5.6 to $65.3 \%$ (all patients). Nighttime BP control was slightly lower than at other time points across all groups. As shown in Table 4, the majority of patients had controlled morning ambulatory BP and clinic BP after treatment (54.1\%); however, $25.8 \%$ had uncontrolled clinic BP and uncontrolled 24-h ambulatory BP $(<125 / 80 \mathrm{~mm} \mathrm{Hg})(22.0 \%$ if $24-\mathrm{h}$ ambulatory $\mathrm{BP}<130 / 80 \mathrm{~mm} \mathrm{Hg}$ ) and $20.3 \%$ had uncontrolled clinic BP but controlled 24-h ambulatory BP $(<125 / 80 \mathrm{~mm} \mathrm{Hg})(15.0 \%$ if 24-h ambulatory BP was $<130 / 80 \mathrm{~mm} \mathrm{Hg}$ ).

The response rate to telmisartan-based treatments was high for both previously untreated and previously treated patients (Table 5). The greatest responses were observed for diastolic ambulatory BP measurements; between 80 and $99.1 \%$ of previously untreated and previously treated patients achieved ambulatory DBP response rates $(\geqslant 10 \mathrm{~mm} \mathrm{Hg}$ BP decrease) following treatment with telmisartan and telmisartan plus HCTZ. In total, the early morning SBP/DBP response rates were $42.6 \%$ and $88.4 \%$, respectively. Daytime

Table 2 Mean change in SBP/DBP $(\mathrm{mm} \mathrm{Hg})$ from baseline after 8 weeks of treatment with telmisartan or telmisartan plus HCTZ

\begin{tabular}{|c|c|c|c|c|c|}
\hline & Previously treated patients & \multicolumn{2}{|c|}{ Previously untreated patients } & \multicolumn{2}{|c|}{ All patients } \\
\hline & Telmisartan & Telmisartan plus HCTZ & Telmisartan & Telmisartan plus HCTZ & treatment \\
\hline \multicolumn{6}{|l|}{ Clinic $(m m H g)$} \\
\hline SBP/DBP, $n$ & $-22.01^{a} /-13.25^{a}, n=169$ & $-21.72^{a} /-13.15^{a}, n=109^{c}$ & $-26.00^{\mathrm{a}} /-11.78^{\mathrm{b}}, n=9$ & $-18.24^{a} /-14.65^{a}, n=17$ & $-22.32 /-13.20^{a}$ \\
\hline \multicolumn{6}{|l|}{ Ambulatory $B P(\mathrm{~mm} \mathrm{Hg})$} \\
\hline Morning SBP/DBP, $n$ & $-5.36^{a} /-3.07^{a}, n=235$ & $-8.82^{a} /-5.43^{a}, n=168$ & $-9.78^{a} /-5.92^{a}, n=165$ & $-9.52^{\mathrm{a}} /-6.48^{\mathrm{a}}, n=90$ & $-8.16 /-4.88^{a}$ \\
\hline Daytime SBP/DBP, $n$ & $-5.24^{\mathrm{a}} /-2.88^{\mathrm{a}}, n=235$ & $-8.18^{\mathrm{a}} /-4.92^{\mathrm{a}}, n=168$ & $-9.52^{a} /-6.15^{a}, n=165$ & $-10.01^{a} /-6.58^{a}, n=90$ & $-7.96 /-4.73^{a}$ \\
\hline Nighttime SBP/DBP, $n$ & $-5.94^{a} /-3.27^{a}, n=235$ & $-8.17^{a} /-4.80^{a}, n=168$ & $-7.92^{\mathrm{a}} /-4.90^{\mathrm{a}}, n=165$ & $-9.91^{a} /-7.34^{a}, n=90$ & $-7.64 /-4.66^{a}$ \\
\hline 24-h SBP/DBP, $n$ & $-5.47^{a} /-3.01^{a}, n=235$ & $-8.15^{a} /-4.87^{a}, n=168$ & $-8.97^{a} /-5.72^{a}, n=165$ & $-9.98^{a} /-6.84^{a}, n=90$ & $-7.85 /-4.70^{a}$ \\
\hline
\end{tabular}

Abbreviations: BP, blood pressure; DBP, diastolic blood pressure; HCTZ, hydrochlorothiazide; SBP, systolic blood pressure.

a $P<0.001$ vs. baseline.

b $P<0.008$ vs. baseline.

c109 patients had SBP measurements available but only 108 patients had DBP measurements available.

Table 3 BP control rates (\%) initially and after 8 weeks of treatment with telmisartan or telmisartan plus HCTZ

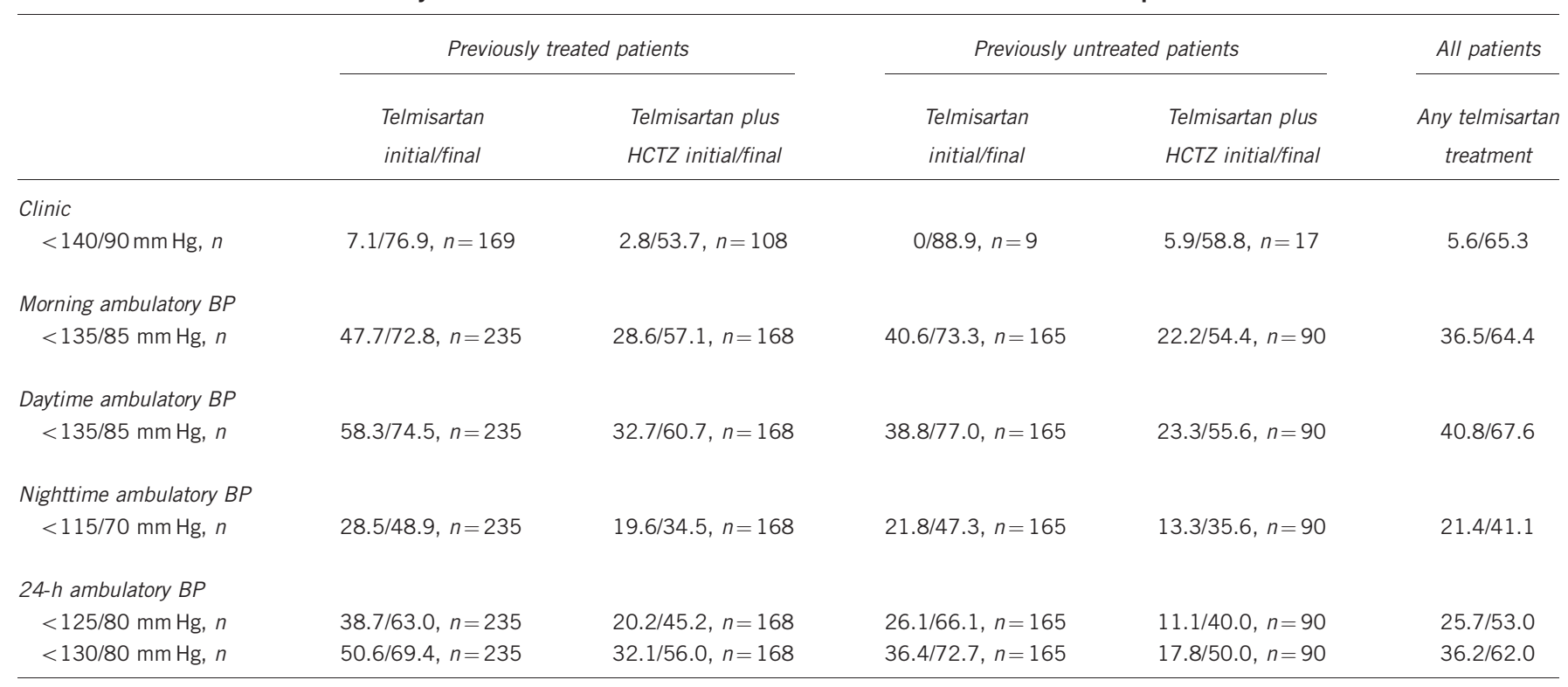

Abbreviations: BP, blood pressure; HCTZ, hydrochlorothiazide. 
Table 4 Ambulatory BP control (final visit) according to the level of clinic BP control achieved with telmisartan or telmisartan plus HCTZ (all patients; $n=863$ )

\begin{tabular}{|c|c|c|c|}
\hline & $\begin{array}{c}\text { Clinic BP } \\
<140 / 90 \mathrm{~mm} \mathrm{Hg}\end{array}$ & $\begin{array}{c}\text { Clinic BP } \\
\geqslant 140 / 90 \mathrm{~mm} \mathrm{Hg}\end{array}$ & $\begin{array}{l}\text { P-value } \\
\chi^{2} \text { test }\end{array}$ \\
\hline \multicolumn{4}{|c|}{ Morning ambulatory $B P(<135 / 85 \mathrm{~mm} \mathrm{Hg})$} \\
\hline Not controlled, $n(\%)$ & $77(10.8)$ & $155(21.7)$ & $<0.0001$ \\
\hline Controlled, $n(\%)$ & $386(54.1)$ & 95 (13.3) & \\
\hline \multicolumn{4}{|c|}{ 24- $h$ ambulatory $B P(<125 / 80 \mathrm{~mm} \mathrm{Hg})$} \\
\hline Not controlled, $n(\%)$ & $48(6.7)$ & $184(25.8)$ & $<0.0001$ \\
\hline Controlled, $n(\%)$ & $336(47.1)$ & $145(20.3)$ & \\
\hline \multicolumn{4}{|c|}{ 24- $h$ ambulatory $B P(<130 / 80 \mathrm{~mm} \mathrm{Hg})$} \\
\hline Not controlled, $n(\%)$ & 75 (10.5) & $157(22.0)$ & $<0.0001$ \\
\hline Controlled, $n(\%)$ & $374(52.5)$ & $107(15.0)$ & \\
\hline
\end{tabular}

Abbreviations: BP, blood pressure; $\mathrm{HCTZ}$, hydrochlorothiazide.

ambulatory SBP/DBP response rates were $43.2 \%$ and $89.7 \%$; 24 -h ambulatory SBP/DBP response rates were $41.4 \%$ and $94.6 \%$; and clinic SBP and DBP response rates were $74.1 \%$ and $77.1 \%$, respectively. The majority of patients $(67.2 \% ; 580 / 863)$ rated the efficacy of telmisartan and telmisartan plus HCTZ as 'very good'; $21.6 \%$ (186/ 863 ) rated it as 'good' and $0.8 \%(7 / 863)$ rated it as 'bad'.

\section{Safety}

The tolerability of telmisartan and telmisartan plus HCTZ was rated as 'very good' by $87.3 \%$ (753/863); as 'good' by $6.6 \%$ (57/863); and as 'bad' by $<1 \%(1 / 863)$. The percentage of patients with any adverse event was $0.8 \%$ (7/863); the most commonly reported adverse events (all $0.2 \%$ ) were anguish, diarrhea, dyspnea, headache, palpitations and shortness of breath. Only one treatment-related adverse event (dermatosis) was reported. Of those patients who received concomitant ACE inhibitor therapy, only $0.8 \%(2 / 250)$ reported adverse events.

\section{DISCUSSION}

This observational study (SURGE 2), which was performed in 863 patients, showed that telmisartan alone or in combination with HCTZ significantly reduced morning ambulatory SBP and DBP in both treated (and uncontrolled) and untreated hypertensive patients; $64.4 \%$ of all patients achieved the target morning ambulatory BP of $<135 / 85 \mathrm{~mm} \mathrm{Hg}$ after 8 weeks of telmisartan-based treatment, which was approximately twice that observed at baseline. The overall mean change in morning ambulatory BP was significant for all patients. Similar improvements were observed for daytime ambulatory BP and 24-h ambulatory BP. The recommended 24-h ambulatory BP targets $\left(<125 / 80 \mathrm{~mm} \mathrm{Hg}^{14}\right.$ and $\left.<130 / 80 \mathrm{~mm} \mathrm{Hg}^{15}\right)$ were achieved by $53 \%$ and $62 \%$ of all patients, respectively, following telmisartan-based treatments. It is also interesting to note that the benefits observed in previously untreated and treated patients were comparable irrespective of age differences or differences in comorbid illnesses. In terms of safety, only $0.8 \%$ of patients reported adverse events; however, it should be highlighted that this short study was not designed to assess safety.

Previous studies have shown that the combination of telmisartan plus HCTZ significantly reduced both clinic BP and ambulatory
Table 5 Response rates (defined as a percentage of patients with $\geqslant 10 \mathrm{~mm} \mathrm{Hg}$ reduction in SBP or DBP from ambulatory BP or clinic BP baseline) after 8 weeks of treatment with telmisartan or telmisartan plus HCTZ

\begin{tabular}{|c|c|c|c|c|c|}
\hline & \multicolumn{2}{|c|}{ Previously treated patients } & \multicolumn{2}{|c|}{$\begin{array}{l}\text { Previously untreated } \\
\text { patients }\end{array}$} & \multirow{2}{*}{$\begin{array}{c}\text { All patients } \\
\text { Any telmisartan } \\
\text { treatment }\end{array}$} \\
\hline & Telmisartan & $\begin{array}{l}\text { Telmisartan } \\
\text { plus HCTZ }\end{array}$ & Telmisartan & $\begin{array}{l}\text { Telmisartan } \\
\text { plus HCTZ }\end{array}$ & \\
\hline \multicolumn{6}{|l|}{ Clinic } \\
\hline SBP & 76.9 & 73.4 & 77.8 & 64.7 & 74.1 \\
\hline DBP & 77.5 & 74.1 & 100.0 & 82.4 & 77.1 \\
\hline$n$ & 169 & $109^{a}$ & 9 & 17 & \\
\hline \multicolumn{6}{|c|}{ Morning ambulatory BP } \\
\hline SBP & 32.8 & 48.8 & 49.7 & 41.1 & 42.6 \\
\hline DBP & 95.3 & 85.7 & 87.3 & 80.0 & 88.4 \\
\hline$n$ & 235 & 168 & 165 & 90 & \\
\hline \multicolumn{6}{|c|}{ Daytime ambulatory BP } \\
\hline SBP & 30.2 & 46.4 & 52.1 & 47.8 & 43.2 \\
\hline DBP & 95.7 & 86.3 & 88.5 & 80.0 & 89.7 \\
\hline$n$ & 235 & 168 & 165 & 90 & \\
\hline \multicolumn{6}{|c|}{ Nighttime ambulatory $B P$} \\
\hline SBP & 32.8 & 46.4 & 40.0 & 46.7 & 40.6 \\
\hline DBP & 99.1 & 98.2 & 98.8 & 93.3 & 98.3 \\
\hline$n$ & 235 & 168 & 165 & 90 & \\
\hline \multicolumn{6}{|c|}{ 24-h ambulatory $B P$} \\
\hline SBP & 28.9 & 45.8 & 47.9 & 45.6 & 41.4 \\
\hline DBP & 97.9 & 92.3 & 93.9 & 91.1 & 94.6 \\
\hline$n$ & 235 & 168 & 165 & 90 & \\
\hline
\end{tabular}

Abbreviations: BP, blood pressure; DBP, diastolic blood pressure; HCTZ, hydrochlorothiazide; SBP, systolic blood pressure.

a 109 patients had SBP measurements available, but only 108 patients had DBP measurements available.

BP. ${ }^{16,17}$ In our study, the BP control rates achieved with combination therapy were lower than those observed with monotherapy in both previously treated and previously untreated patients; however, these findings were not unexpected, given that this was a practice-based study and physicians prescribed according to needs, that is, those patients on combination therapy would be those that were more difficult to control.

It was also interesting to note that the analyses were performed on patients using only telmisartan or telmisartan plus HCTZ at final visit. Even though the combination control rates were lower than monotherapy control rates, the majority of previously treated patients using telmisartan plus HCTZ $(68.8 \%$ (168/244)) achieved these improved control rates, having switched to this combination with no additional medication.

In the current study, the mean post-treatment improvement from baseline remained consistently around $6-10 \mathrm{~mm} \mathrm{Hg}$ over the $24-\mathrm{h}$ period. This improvement was also evident in the morning hours, the period that has been shown to correlate with peak incidences of cerebro- and cardiovascular events. ${ }^{2-5}$ Previous studies have shown that a $2-10 \mathrm{~mm} \mathrm{Hg}$ lower BP is associated with a significantly lower risk of a cardiovascular event. ${ }^{18,19}$ The reduction achieved by the telmisartan-based treatments used in this community-based study, 
even during the risky morning hours, is likely to reduce the risk of vascular events. A limitation of a practice-based study is the lack of a control; it is possible that some of the improvement observed with clinic BP may be due, in part, to a removal of the 'white-coat' effect. All patients entered the study with uncontrolled clinic BP ( $>140 / 90 \mathrm{~mm} \mathrm{Hg}$ ); however, during the baseline visit, $5.9 \%$ of previously untreated patients had controlled clinic BP, which is suggestive of initial white-coat effect. There was evidence to suggest that up to $20 \%$ of patients had white-coat hypertension (uncontrolled clinic BP and controlled 24-h ambulatory BP) at final visit, though around a quarter of patients may have had sustained hypertension (uncontrolled clinic BP and 24-h ambulatory BP). Some patients who initially started on either telmisartan or on telmisartan plus HCTZ switched during the study or changed dose, which could have led to bias in the final assessments.

Overall, the findings from the present study show that telmisartanbased therapies improve BP during the morning hours when vascular events, such as stroke or myocardial infarction, are most likely to happen. Furthermore, the BP effect is maintained throughout the 24-h period with both therapies, telmisartan and telmisartan plus HCTZ. This study also supports the findings from previous community-based studies that have assessed the benefits of telmisartan. In a study of more than 1500 patients, both the clinic BP and ambulatory SBP and DBP were significantly improved by the addition of telmisartan with or without HCTZ. ${ }^{20}$ In the MICARDIS Community Ambulatory Monitoring Trial 2 (MICCAT-2), the mean reduction in early morning BP after treatment with telmisartan-based therapies was $-11.5 /-7.0 \mathrm{~mm} \mathrm{Hg}$; this study was based on a cohort of more than 1600 treated or untreated patients. $^{21}$

In conclusion, this study showed that once-daily telmisartan or telmisartan plus HCTZ improved morning ambulatory BP control and maintained a smooth $24-\mathrm{h}$ ambulatory BP profile in both previously treated and untreated patients. The reduction in morning ambulatory BP and maintenance of smooth BP may help to minimize the risk of cardiovascular events.

\section{CONFLICT OF INTEREST}

The authors declare no conflict of interest.

\section{ACKNOWLEDGEMENTS}

We thank all investigators who comprised the SURGE Steering Committee for their participation in terms of patient involvement, data collection and analyses. Writing and editorial assistance was provided by PAREXEL, which was contracted by Boehringer Ingelheim International $\mathrm{GmbH}$ for these services, data analysis was provided by Quintiles.

\section{DISCLAIMER}

The author meets the criteria for authorship as recommended by the International Committee of Medical Journal Editors (ICMJE) and was fully responsible for all content and editorial decisions, and was involved at all stages of manuscript development. The author received no compensation related to the development of the manuscript. The SURGE series of trials was sponsored by Boehringer Ingelheim International $\mathrm{GmbH}$.
1 Straus SE, Majumdar SR, McAlister FA. New evidence for stroke prevention: scientific review. JAMA 2002; 288: 1388-1395.

2 Kario K, Pickering TG, Umeda Y, Hoshide S, Hoshide Y, Morinari M, Murata M, Kuroda T, Schwartz JE, Shimada K. Morning surge in blood pressure as a predictor of silent and clinical cerebrovascular disease in elderly hypertensives: a prospective study. Circulation 2003; 107: 1401-1406.

3 Marler JR, Price TR, Clark GL, Muller JE, Robertson T, Mohr JP, Hier DB, Wolf PA, Caplan LR, Foulkes MA. Morning increase in onset of ischemic stroke. Stroke 1989; 20: 473-476.

4 Muller JE, Stone PH, Turi ZG, Rutherford JD, Czeisler CA, Parker C, Poole WK, Passamani $E$, Roberts R, Robertson T. Circadian variation in the frequency of onset of acute myocardial infarction. N Eng/ J Med 1985; 313: 1315-1322.

5 Parati G. Blood pressure variability: its measurement and significance in hypertension. $J$ Hypertens 2005; 23: S19-S25.

6 White WB. Relevance of blood pressure variation in the circadian onset of cardiovascular events. J Hypertens Supp/ 2003; 21: S9-15.

7 Redon J, Roca-Cusachs A, Mora-Macia J. Uncontrolled early morning blood pressure in medicated patients: the ACAMPA study. Analysis of the Control of Blood Pressure using Abulatory Blood Pressure Monitoring. Blood Press Monit 2002; 7: 111-116.

8 Polonia J, Alcantara P, Amado P, Silva JA, Nazare J, Braz-Nogueira J, Martins L, Carmona J. Lack of adequate blood pressure control in the morning and evening periods in medicated hypertensive patients considered to be controlled in the office. Rev Port Cardiol 2005; 24: 1059-1072.

9 Gosse P, Neutel JM, Schumacher H, Lacourciere Y, Williams B, Davidai G. The effect of telmisartan and ramipril on early morning blood pressure surge: a pooled analysis of two randomized clinical trials. Blood Press Monit 2007; 12: 141-147.

10 Williams B, Gosse P, Lowe L, Harper R. The prospective, randomized investigation of the safety and efficacy of telmisartan versus ramipril using ambulatory blood pressure monitoring (PRISMA I). J Hypertens 2006; 24: 193-200.

11 White WB, Punzi HA, Murwin D, Koval SE, Davidai G, Neutel JM. Effects of the angiotensin II receptor blockers telmisartan vs. valsartan in combination with hydrochlorothiazide $25 \mathrm{mg}$ once daily for the treatment of hypertension. J Clin Hypertens 2006; 8: 626-633.

12 Chobanian AV, Bakris GL, Black HR, Cushman WC, Green LA, Izzo Jr JL, Jones DW, Materson BJ, Oparil S, Wright Jr JT, Roccella EJ. The Seventh Report of the Joint National Committee on Prevention, Detection, Evaluation, and Treatment of High Blood Pressure: the JNC 7 report. JAMA 2003; 289: 2560-2572.

13 O'Brien E, Asmar R, Beilin L, Imai Y, Mallion JM, Mancia G, Mengden T, Myers M, Padfield P, Palatini P, Parati G, Pickering T, Redon J, Staessen J, Stergiou G, Verdecchia P. European Society of Hypertension recommendations for conventional, ambulatory and home blood pressure measurement. J Hypertens 2003; 21: 821-848.

142003 European Society of Hypertension. European Society of Cardiology guidelines for the management of arterial hypertension. J Hypertens 2003; 21: 1011-1053.

15 Pickering TG, Hall JE, Appel LJ, Falkner BE, Graves J, Hill MN, Jones DW, Kurtz T, Sheps SG, Roccella EJ. Recommendations for blood pressure measurement in humans and experimental animals: Part 1: blood pressure measurement in humans: a statement for professionals from the Subcommittee of Professional and Public Education of the American Heart Association Council on High Blood Pressure Research. Hypertension 2005; 45: 142-161.

16 Lacourciere Y, Neutel JM, Schumacher H. Comparison of fixed-dose combinations of telmisartan/hydrochlorothiazide $40 / 12.5 \mathrm{mg}$ and $80 / 12.5 \mathrm{mg}$ and a fixed-dose combination of losartan/hydrochlorothiazide $50 / 12.5 \mathrm{mg}$ in mild to moderate essential hypertension: pooled analysis of two multicenter, prospective, randomized, open-label, blinded-end point (PROBE) trials. Clin Ther 2005; 27: 1795-1805.

17 McGill JB, Reilly PA. Telmisartan plus hydrochlorothiazide versus telmisartan or hydrochlorothiazide monotherapy in patients with mild to moderate hypertension: a multicenter, randomized, double-blind, placebo-controlled, parallel-group trial. Clin Ther 2001; 23: 833-850.

18 Lewington S, Clarke R, Qizilbash N, Peto R, Collins R. Age-specific relevance of usual blood pressure to vascular mortality: a meta-analysis of individual data for one million adults in 61 prospective studies. Lancet 2002; 360: 1903-1913.

19 Sega R, Facchetti R, Bombelli M, Cesana G, Corrao G, Grassi G, Mancia G. Prognostic value of ambulatory and home blood pressures compared with office blood pressure in the general population: follow-up results from the Pressioni Arteriose Monitorate e Loro Associazioni (PAMELA) study. Circulation 2005; 111: 1777-1783.

20 White WB, Giles T, Bakris GL, Neutel JM, Davidai G, Weber MA. Measuring the efficacy of antihypertensive therapy by ambulatory blood pressure monitoring in the primary care setting. Am Heart J 2006; 151: 176-184.

21 White WB, Weber MA, Davidai G, Neutel JM, Bakris GL, Giles T. Ambulatory blood pressure monitoring in the primary care setting: assessment of therapy on the circadian variation of blood pressure from the MICCAT-2 Trial. Blood Press Monit 2005; 10 : 157-163. 